\title{
Deoxidation Equilibria of Vanadium, Niobium, and Tantalum in Liquid Iron*
}

\author{
By Kiichi NARITA ${ }^{* *}$ and Shinji KOYAMA**
}

\begin{abstract}
Synopsis
The deoxidation reactions of vanadium, niobium, and tantalum in liquid iron are as follows: in the range of a comparatively large concentration of these elements, $2 \underline{\mathrm{V}}+3 \underline{\mathrm{O}}=\mathrm{V}_{2} \mathrm{O}_{3}, \underline{\mathrm{Nb}}+2 \underline{\mathrm{O}}=\mathrm{NbO}_{2}, 2 \underline{\mathrm{Ta}}+5 \underline{\mathrm{O}}=\mathrm{Ta}_{2}$ $\mathrm{O}_{5}$ and in the range of a small concentration of these elements, $\mathrm{Fe}(l)+2 \underline{\mathrm{V}}$ $+4 \underline{\mathrm{Q}}=\mathrm{FeO} \cdot \mathrm{V}_{2} \mathrm{O}_{3}, \quad \mathrm{Fe}(l)+2 \underline{\mathrm{Nb}}+6 \underline{\mathrm{Q}}=\mathrm{FeO} \cdot \mathrm{Nb}_{2} \mathrm{O}_{5}, \quad \mathrm{Fe}(l)+2 \underline{\mathrm{Ta}}$ $+6 \underline{\mathrm{Q}}=\mathrm{FeO} \cdot \mathrm{Ta}_{2} \mathrm{O}_{5}$, respectively. The deoxidizing powers of vanadium, niobium, and tantalum become larger as the atomic number increases. Correspondingly, the influences of these elements on the activity of oxygen become larger in the order of atomic number.
\end{abstract}

\section{Introduction}

Vanadium, niobium, and tantalum, which belong to the group $\mathrm{V}$-a in the periodic table, are regarded as very interesting alloying elements for steel. These elements have less affinity with oxygen as compared with aluminum and other elements of the group IV-a and, therefore, are not so easily oxidized in liquid steel. Besides they usually form carbides or nitrides which have an appropriate solubility in solid steel.

Up to the present, such researches as the basic reactions of these elements in steelmaking process, the dissolution and the precipitation reactions of their carbides and nitrides in solid steel, and the effects of them on some properties of steel have been conducted by the authors.

Among these, the results obtained for the study on the deoxidation reactions of vanadium, niobium, and tantalum in liquid iron are summarized in this paper.

\section{Experimental}

1. Determination of the Equilibrium between Liquid Iron Containing Alloying Element and Water Vapor-Hydrogen

The experimental method is the same as the one commonly used for the determination of the deoxidation equilibrium in liquid iron. That is, the electrolytic iron weighing 50 to $180 \mathrm{~g}$ was melted in an alumina crucible*** with a high frequency induction furnace, and reduced by hydrogen for 30 to $60 \mathrm{~min}$ at a specified temperature.

Then, vanadium, niobium, or tantalum was added to the liquid iron. Hydrogen, which was passed through the steam saturator set in the water bath with a thermostat, was regulated at a fixed partial pressure ratio of water vapor and hydrogen $\left(P_{\mathrm{H}_{2} \mathrm{O}} / P_{\mathrm{H}_{2}}\right)$, and then, diluted with argon to the ratio $\mathrm{H}_{2}: \mathrm{A}=1: 5$ to prevent the thermal diffusion of the mixed gas. This gas mixture was blown to the surface of liquid iron for the reaction through the alumina tube heated by molybdenum wire at the temperature range $1000^{\circ}$ to $1200^{\circ} \mathrm{C}$. The flow rate of gas mixture was kept at about $600 \mathrm{ml} / \mathrm{min}$, and the tip of the alumina tube was set at the distance 3 to $5 \mathrm{~mm}$ from the surface of the melt. Under the condition that liquid iron was saturated with the oxide, the partial pressure ratio $\left(P_{\mathrm{H}_{2} \mathrm{O}} /\right.$ $P_{\mathrm{H}_{2}}$ ) was gradually raised and then fixed at such a constant ratio that the oxide was formed on the surface of the melt. Under this condition, the liquid iron was equilibrated with the gas mixture for two hours. The sample was taken out of the liquid iron with a silica tube by suction and quenched in water, and then subjected to the chemical analysis. In some experiments, the crucible was brought down to the lower part of the reaction chamber and cooled by blowing argon and then the sample for the chemical analysis was taken out of the solidified ingot.

The experimental temperature was measured by an optical pyrometer calibrated, and simultaneously by a two-colour pyrometer continuously, for controlling the temperature.

\section{Identification of the Deoxidation Products}

In order to clarify the deoxidation reactions of vanadium, niobium, and tantalum in liquid iron, the oxides were identified by the following methods:

(1) Electron diffraction of the oxide formed on the surface of liquid iron while determining the equilibrium,

(2) X-ray diffraction of the oxide extracted from the ingot which was solidified in the crucible by blowing argon or furnace cooling, and

(3) Electron and X-ray diffractions of oxides extracted from samples, either quenched after the reaction of liquid iron in the one end sealed silica tube with a certain amount of the deoxidation element previously inserted in it, or taken out with a silica tube by suction and quenched immediately after the addition of a certain amount of the deoxidation element to the melt.

\section{Experimental Results and Discussion}

1. The Equilibrium of the Reaction between Liquid Iron and Water Vapor-Hydrogen

According to the experimental results on the reaction represented by Eq. 1, there is a linear relation having the negative slope between the apparent equilibrium

* Presented at the 71st ISIJ Meeting, April, 1966 in Tokyo, 74th, October, 1967 in Sapporo, and Cernov Centennial Symposium, May, 1968 in Moscow. Manuscript received June 21, 1968.

** Central Research Laboratory, Kobe Steel, Ltd., Wakihamacho, Fukiai-ku, Kobe 651.

*** In some experiments for the reaction $\mathrm{Fe}(l)-\mathrm{Nb}-\mathrm{H}_{2} \mathrm{O} / \mathrm{H}_{2}$, silica crucible was used instead of alumina. 
constant, $\log K_{1}^{\prime}=\log \left(P_{\mathrm{H}_{2} \mathrm{O}} / P_{\mathrm{H}_{2}} \cdot[\% \mathrm{O}]\right)$ and the oxygen content $[\% \mathrm{O}]$.

$$
\mathrm{H}_{2}+\underline{\mathrm{O}}=\mathrm{H}_{2} \mathrm{O}
$$

Namely, the activity coefficient of oxygen decreases as the oxygen content in liquid iron increases. From the slope of the straight line, the interaction parameter, $e_{\mathrm{o}}^{\prime}$, was obtained, and is shown in Fig. 1. Besides, the equilibrium constant for the reaction of Eq. 1 is shown in Fig. 2, and is expressed by the relation of Eq. 2 .

$$
\log K_{1}=\log \left(P_{\mathrm{H}_{2} \mathrm{O}} / P_{\mathrm{H}_{2}} \cdot a_{\mathrm{O}}\right)=6980 / T-3.171 \ldots \ldots
$$

This result agrees comparatively well with the results recently reported by the other investigators. ${ }^{1)-6 \text { ) }}$

\section{The Equilibrium of the Reaction between Liquid Iron Containing Vanadium and Water Vapor-Hydrogen ${ }^{7), 8)}$}

In case that liquid iron is saturated with vanadium oxide, equilibrium relations between the vanadium content $[\% \mathrm{~V}]$ in liquid iron and the partial pressure ratio $\left(P_{\mathrm{H}_{2} \mathrm{O}} / P_{\mathrm{H}_{2}}\right)$ are plotted in Fig. 3. As the results, two straight lines having slopes of $-2 / 3$ and $-1 / 2$ were drawn depending on the vanadium content more than 0.1 to $0.5 \%$ and less, respectively.

On the other hand, the oxide film formed on the surface of liquid iron was identified by electron diffraction as vanadium trioxide, $\mathrm{V}_{2} \mathrm{O}_{3}$ at the vanadium content beyond 0.1 to $0.5 \%$, and as ferrous vanadate, $\mathrm{FeV}_{2} \mathrm{O}_{4}$ below that range of vanadium content. The compositions of both oxides respectively correspond to the results expected from the slopes of the foregoing linear relation between logarithms of the vanadium content and the partial pressure ratio.

According to the study of Samarin and others, ${ }^{91}$ vanadium trioxide, $\mathrm{V}_{2} \mathrm{O}_{3}$ is equilibrated as the deoxidation product only in a narrow range of vanadium

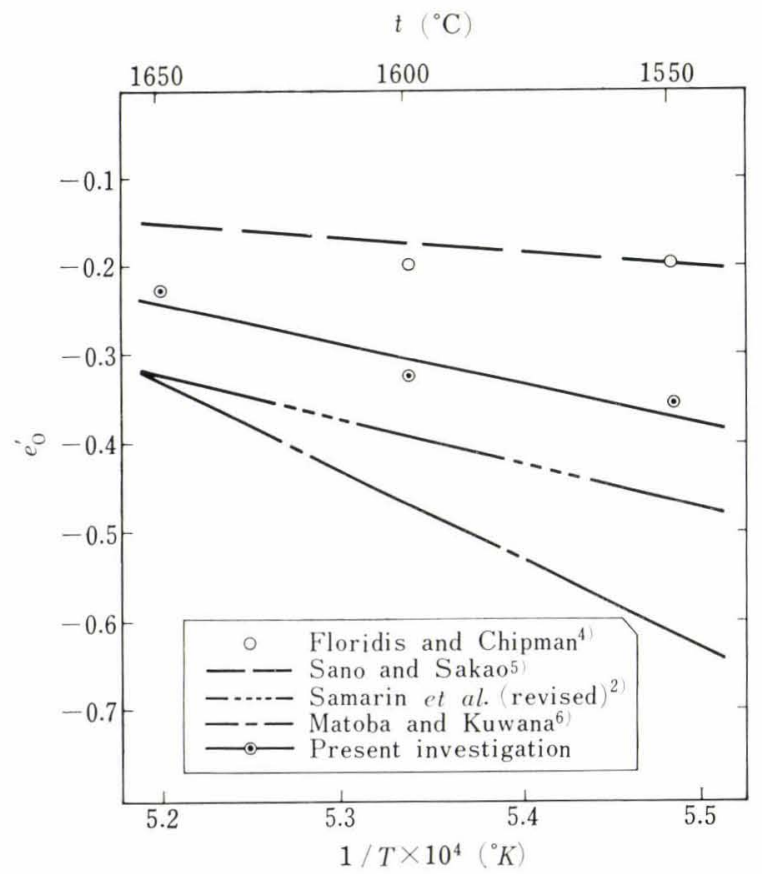

Fig. 1. Relation between $e_{0}^{\prime}$ and $1 / T$ content, such as 0.2 to $0.3 \%$. They found that, in case of the liquid iron containing vanadium more than that content, the linear relation between logarithms of the vanadium content and the partial pressure ratio had the slope of -1 , and that the equilibrated oxide was $\mathrm{V}_{2} \mathrm{O}_{2}$, vanadium monoxide.

However, in our experimental results ${ }^{8)}$ at $1600^{\circ} \mathrm{C}$, the slope of $-2 / 3$ did not change even when 3 to $4 \%$ of vanadium was added. Moreover, the oxide electrolytically extracted from the solidified ingot containing about $1 \%$ of vanadium was identified to be $\mathrm{V}_{2} \mathrm{O}_{3}$ by $\mathrm{X}$-ray diffraction. There are still questions as to which of $\mathrm{V}_{2} \mathrm{O}_{3}$ or $\mathrm{V}_{2} \mathrm{O}_{2}$ the primary deoxidation product is. The above-mentioned oxide is considered to be the socalled secondary deoxidation product precipitated during the period of freezing. The existence of $\mathrm{V}_{2} \mathrm{O}_{2}$ observed by Samarin and others has not been found in the current work.

3. The Equilibrium of the Reaction between Liquid Iron Containing Niobium and Water Vapor-Hydrogen ${ }^{10}$

\section{$t\left({ }^{\circ} \mathrm{C}\right)$}

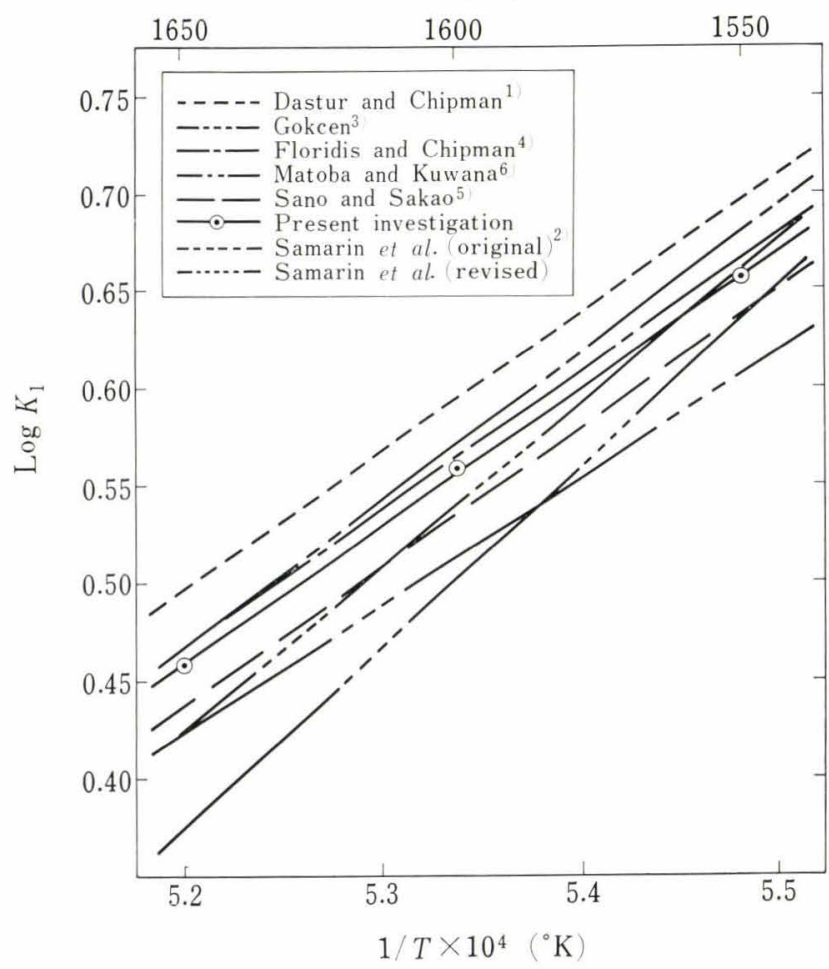

Fig. 2. Relation between $\log K_{1}$ and $1 / T$

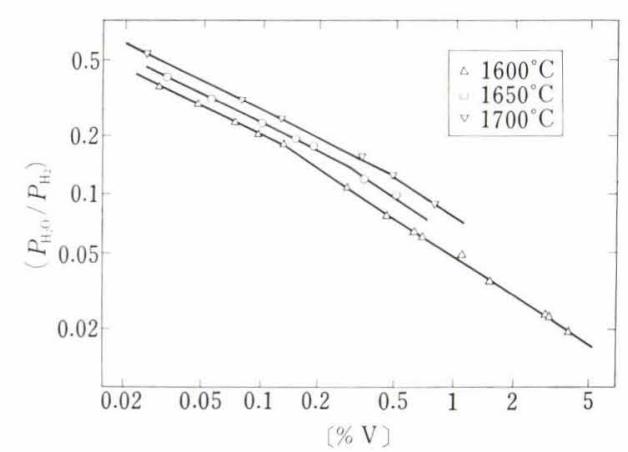

Fig. 3. Equilibrium in the reaction of water vapor-hydrogen with vanadium in liquid iron 
The equilibrium relation between the partial pressure ratio $\left(P_{\mathrm{H}_{2} \mathrm{O}} / P_{\mathrm{H}_{2}}\right)$ and the niobium content $[\% \mathrm{Nb}]$ which was measured under the condition where the liquid iron was saturated with niobium oxide is shown in Fig. 4. Two straight lines having the different slopes were drawn on the logarithmic plot of the partial pressure ratio $\left(P_{\mathrm{H}_{2} \mathrm{O}} / P_{\mathrm{H}_{2}}\right)$ against the niobium content $[\% \mathrm{Nb}]$. The slope of the straight line is $-1 / 2$ in case that liquid iron contains niobium more than 0.3 to $0.5 \%$, and is nearly $-1 / 3$ in case less than that content.

In order to identify the deoxidation product, the residual oxide extracted from the solidified ingot by

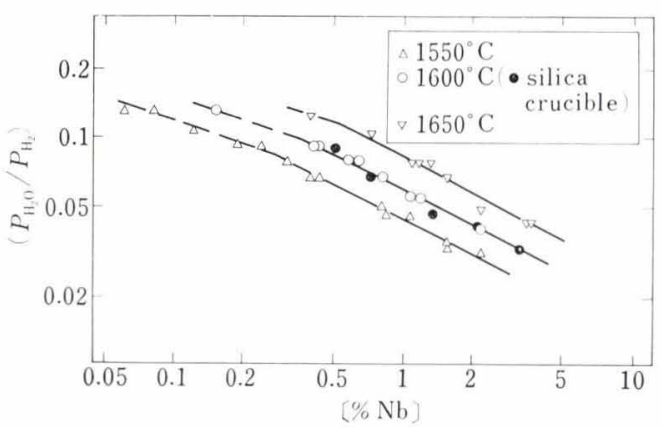

Fig. 4. Equilibrium in the reaction of water vapor-hydrogen with niobium in liquid iron diluted hydrochloric acid was examined by X-ray diffraction method, and the oxide film formed on the surface of the ingot by electron diffraction method. Those results are shown in Table 1. Almost all patterns accord well with those of niobium dioxide, $\mathrm{NbO}_{2}$ having the tetragonal structure. It is supposed that the oxide examined by the electron diffraction contains some secondary deoxidation product which is precipitated and floated on the ingot surface during the period of freezing. However, most of the oxide is considered to be the primary deoxidation product which is formed on the surface of liquid iron during the period of equilibration with water vapor-hydrogen gas mixture, while the oxide examined by X-ray diffraction is perhaps the secondary deoxidation product. It is recognized that the diffraction patterns of both oxides fairly well correspond to each other. Therefore, $\mathrm{NbO}_{2}$ with tetragonal structure of the rutile type is considered to be equilibrated as the deoxidation product in the liquid iron containing niobium more than 0.3 to $0.5 \%$.

Meanwhile, it was too difficult to identify the oxide formed on the surface of the melt containing less than 0.3 to $0.5 \%$ niobium. In this case, the oxide was therefore extracted from the solidified ingot and analysed by X-ray method. According to the results, the different patterns from those of $\mathrm{NbO}_{2}$ are observed

Table 1. X-ray and electron diffraction patterns of the niobium oxides

\begin{tabular}{|c|c|c|c|c|c|c|}
\hline \multicolumn{2}{|c|}{$\mathrm{NbO}_{2}{ }^{*}$} & \multicolumn{2}{|c|}{$\mathrm{NbO}_{2} * *$} & \multicolumn{2}{|c|}{$\mathrm{X}$-ray diffraction patterns $* * *$} & \multirow{2}{*}{$\begin{array}{c}\text { Electron } * * * * \\
\text { diffraction patterns } \\
d(\AA)\end{array}$} \\
\hline$d(\AA)$ & $\mathrm{I} / \mathrm{I}_{1}$ & $d(\AA)$ & $\mathrm{I} / \mathrm{I}_{1}$ & $d(\AA)$ & Intensity & \\
\hline 5.63 & 20 & 3.41 & 100 & 3.37 & V.S & 4.42 \\
\hline 4.29 & 20 & 2.54 & 100 & 2.54 & $\mathrm{~S}$ & 3.40 \\
\hline 3.63 & 30 & 2.42 & 50 & 2.38 & W & 2.68 \\
\hline 3.42 & 100 & 2.25 & 30 & 2.25 & W & 2.55 \\
\hline 3.21 & 30 & 1.90 & 20 & 1.74 & $\mathrm{~S}$ & 1.75 \\
\hline 2.91 & 30 & 1.86 & 20 & 1.69 & M & 1.57 \\
\hline 2.54 & 80 & 1.80 & 20 & 1.51 & M & 1.34 \\
\hline 2.491 & 30 & 1.76 & 100 & 1.41 & M & 1.28 \\
\hline 2.422 & 50 & 1.71 & 70 & 1.37 & W & 1.14 \\
\hline 2.341 & 20 & 1.64 & 20 & 1.28 & V.W & \\
\hline 2.253 & 30 & 1.62 & 20 & 1.21 & M & \\
\hline 2.166 & 20 & 1.57 & 20 & 1.13 & $\mathrm{M}$ & \\
\hline 2.014 & 10 & 1.545 & 70 & & & \\
\hline 1.975 & 20 & 1.500 & 30 & & & \\
\hline 1.932 & 20 & 1.461 & 20 & & & \\
\hline 1.897 & 20 & 1.444 & 20 & & & \\
\hline 1.862 & 20 & 1.422 & 70 & & & \\
\hline 1.829 & 20 & 1.374 & 50 & & & \\
\hline 1.766 & 30 & 1.276 & 40 & & & \\
\hline 1.754 & 80 & 1.230 & 50 & & & \\
\hline 1.712 & 50 & 1.214 & 30 & & & \\
\hline & & 1.179 & 20 & & & \\
\hline & & 1.146 & 40 & & & \\
\hline
\end{tabular}

* $\quad$ Magneli et al.; Acta. Chem. Scand, 9 (1955), 1402.

** G. Brauer; Z. Anorg. Chem., 248 (1941), 4.

*** The oxide extracted from the solidified ingot containing $0.60 \% \mathrm{Nb}$.

**** The oxide formed on the surface of the melt containing $1.08 \% \mathrm{Nb}$. 
and identified to be columbite, $\mathrm{FeO} \cdot \mathrm{Nb}_{2} \mathrm{O}_{5}$. From these facts, it may be said that $\mathrm{FeO} \cdot \mathrm{Nb}_{2} \mathrm{O}_{5}$ is equilibrium oxide.

\section{The Equilibrium of the Reaction between Liquid Iron Containing Tantalum and Water Vapor-Hydrogen}

The equilibrium relation between $\mathrm{H}_{2} \mathrm{O}-\mathrm{H}_{2}$ mixture and tantalum in liquid iron was measured by saturating with the tantalum oxide. The results obtained are shown in Fig. 5. In the same way as the deoxidation equilibria of vanadium and niobium, two straight

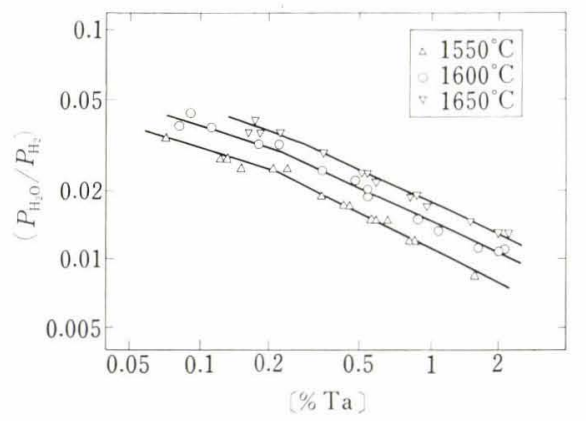

Fig. 5. Equilibrium in the reaction of water vapor-hydrogen with tantalum in liquid iron lines having the different slopes are obtained on the logarithmic plot of the partial pressure ratio $\left(P_{\mathrm{H}_{2} \mathrm{O}} / P_{\mathrm{H}_{2}}\right)$ against the tantalum content $[\% \mathrm{Ta}]$. The slope of the straight line is $-1 / 2$ to $-2 / 5$ in the range where the tantalum content in liquid iron is more than 0.2 to $0.3 \%$, and is nearly $-1 / 3$ in the range where the tantalum is less than that content.

The results of identifying the reaction products by $\mathrm{X}$-ray and electron diffractions are shown in Table 2. From these results, it is considered that the deoxidation product is tantalum pentoxide, $\mathrm{Ta}_{2} \mathrm{O}_{5}$ in liquid iron containing more than 0.2 to $0.3 \%$ tantalum, and tapiolite $(\mathrm{Fe}, 2 \mathrm{Ta}) \mathrm{O}_{6}$ or $\mathrm{FeO} \cdot \mathrm{Ta}_{2} \mathrm{O}_{5}$ in case less than that content.

As shown in Table 2, the diffraction patterns of $\mathrm{Ta}_{2} \mathrm{O}_{5}$, other than those of tapiolite, are considerably strong in the $\mathrm{X}$-ray diffraction of the oxide extracted from the solidified ingot containing $0.08 \%$ tantalum. This may be attributed to the following reason: the authors studied the distribution of tantalum in the lowcarbon steel ingot and found that tantalum was considerably concentrated and segregated in the spaces of the dendrite arms. ${ }^{11)}$ Consequently, it is regarded that tantalum in iron and steel is easily segregated microscopically during the period of freezing. The

Table 2. X-ray diffraction patterns of the tantalum oxides

\begin{tabular}{|c|c|c|c|c|c|c|c|c|c|}
\hline \multirow{2}{*}{\multicolumn{2}{|c|}{ Tapiolite }} & \multirow{2}{*}{\multicolumn{2}{|c|}{$\beta-\mathrm{Ta}_{2} \mathrm{O}_{5}$}} & \multicolumn{6}{|c|}{ Tantalum content of the sample } \\
\hline & & & & \multicolumn{2}{|c|}{$0.24 \% *$} & \multicolumn{2}{|c|}{$0.08 \% * *$} & \multicolumn{2}{|c|}{$0.54 \% * *$} \\
\hline$d(\AA)$ & $\mathrm{I} / \mathrm{I}_{1}$ & $d(\AA)$ & $\mathrm{I} / \mathrm{I}_{1}$ & $d(\AA)$ & Intensity & $d(\AA)$ & Intensity & $d(\AA)$ & Intensity \\
\hline 3.35 & 100 & 3.87 & 90 & 4.23 & W & 4.25 & 14 & 3.88 & 100 \\
\hline 2.58 & 90 & 3.15 & 100 & 3.90 & M & 3.90 & 56 & 3.15 & 90 \\
\hline 2.37 & 50 & 3.09 & 50 & 3.38 & V.S & 3.38 & 100 & 3.11 & 45 \\
\hline 2.27 & 20 & 2.55 & 20 & 3.15 & M & 3.15 & 61 & 2.96 & 12 \\
\hline 2.12 & 10 & 2.46 & 100 & 3.09 & W & 3.12 & 26 & 2.44 & 58 \\
\hline 1.75 & 90 & 2.43 & 60 & 2.80 & M & 2.59 & 92 & 2.42 & 34 \\
\hline 1.678 & 50 & 2.36 & 20 & 2.71 & W & 2.45 & 43 & 2.14 & 12 \\
\hline 1.546 & 20 & 2.02 & $30 B$ & 2.61 & W & 2.38 & 24 & 2.03 & 10 \\
\hline 1.503 & 50 & 1.95 & 50 & 2.58 & $\mathrm{~S}$ & 1.94 & 17 & 1.99 & 11 \\
\hline 1.411 & 50 & 1.83 & 40 & 2.45 & M & 1.80 & 14 & 1.94 & 20 \\
\hline 1.405 & 50 & 1.80 & 40 & 2.42 & W & 1.752 & 81 & 1.80 & 17 \\
\hline 1.298 & 20 & 1.76 & 20 & 2.38 & M & 1.684 & 20 & 1.743 & 10 \\
\hline 1.212 & 40 & 1.661 & 100 & 1.749 & $\mathrm{~S}$ & 1.653 & 34 & 1.725 & 12 \\
\hline 1.189 & 10 & 1.655 & 40 & 1.681 & $\mathrm{M}$ & 1.637 & 13 & 1.653 & 35 \\
\hline 1.154 & 10 & 1.632 & 30 & 1.656 & W & 1.506 & 21 & 1.634 & 16 \\
\hline 1.139 & 20 & 1.582 & 30 & 1.506 & w & 1.408 & 18 & 1.610 & 10 \\
\hline 1.121 & 20 & 1.551 & 30 & 1.410 & W & 1.399 & 19 & & \\
\hline 1.080 & $30 B$ & 1.504 & 20 & 1.395 & W & 1.212 & 14 & & \\
\hline 1.079 & $30 B$ & 1.463 & 40 & 1.212 & W & & & & \\
\hline 1.063 & 10 & 1.441 & 30 & & & & & & \\
\hline & & 1.405 & $30 B$ & & & & & & \\
\hline & & 1.387 & 30 & & & & & & \\
\hline & & 1.338 & 70 & & & & & & \\
\hline & & 1.322 & 60 & & & & & & \\
\hline & & 1.310 & 20 & & & & & & \\
\hline & & 1.300 & 20 & & & & & & \\
\hline
\end{tabular}

* The result examined by the method (3) mentioned in Chapter II-2 experimental

** The result examined by the method (2) 
oxide extracted from the aforementioned sample is supposed to be precipitated during this period. Therefore, it is considered that $\mathrm{Ta}_{2} \mathrm{O}_{5}$ included in the oxide precipitates from the liquid iron containing a fairly large quantity remained in the spaces of the dendrite arms.

5. Deoxidizing Powers of Vanadium, Niobium, and Tantalum and Their Influences on the Activity of Oxygen in Liquid Iron

In the concentration range studied in this work, the deoxidation reactions of vanadium, niobium, and tantalum in liquid iron are as follows: in the range of a comparatively large content of these elements, the chemical reactions and the equilibrium constants are represented by Eqs. (3), (4), and (5),

$$
\begin{array}{r}
2 \underline{\mathrm{V}}+3 \underline{\mathrm{O}}=\mathrm{V}_{2} \mathrm{O}_{3} \ldots \ldots \ldots \ldots \ldots \ldots \ldots \ldots \ldots \ldots \ldots \ldots \ldots \\
\log K=\log a_{\mathrm{V}}^{2} \cdot a_{\mathrm{O}}^{3}=-42300 / T+16.615 \\
\underline{\mathrm{Nb}}+2 \underline{\mathrm{O}}=\mathrm{NbO}_{2} \ldots \ldots \ldots \ldots \ldots \ldots \\
\log K=\log a_{\mathrm{Nb}} \cdot a_{\mathrm{O}}^{2}=-32780 / T+13.917 \\
2 \underline{\mathrm{Ta}}+5 \underline{\mathrm{O}}=\mathrm{Ta}_{2} \mathrm{O}_{5} \ldots \ldots \ldots \ldots \ldots \ldots
\end{array}
$$

$\log K=\log a_{\mathrm{Ta}}^{2} \cdot a_{\mathrm{o}}^{5}=-63100 / T+21.90$

and those for the range of a small content of these elements are represented by Eqs. (6), (7), and (8),

$$
\begin{array}{r}
\mathrm{Fe}(l)+2 \underline{\mathrm{V}}+4 \underline{\mathrm{O}}=\mathrm{FeO} \cdot \mathrm{V}_{2} \mathrm{O}_{3} \ldots \ldots \\
\log K=\log a_{\mathrm{V}}^{2} \cdot a_{\mathrm{O}}^{4}=-44704 / \mathrm{T}+16.508 \\
\mathrm{Fe}(l)+2 \underline{\mathrm{Nb}}+6 \underline{\mathrm{O}}=\mathrm{FeO} \cdot \mathrm{Nb}_{2} \mathrm{O}_{5} \ldots \ldots . \\
\log K=\log a_{\mathrm{Nb}}^{2} \cdot a_{\mathrm{O}}^{6}=-88300 / T+36.76 \\
\mathrm{Fe}(l)+2 \underline{\mathrm{Ta}}+6 \underline{\mathrm{O}}=\mathrm{FeO} \cdot \mathrm{Ta}_{2} \mathrm{O}_{5} \ldots \ldots
\end{array}
$$$$
\log K=\log a_{\mathrm{Ta}}^{2} \cdot a_{0}^{6}=-79300 / T+28.43
$$

The atomic ratio $\left(\mathrm{O} / \mathrm{M}_{\mathrm{V}, \mathrm{Nb}, \mathrm{Ta}}\right)$ of oxygen to the metal element in the deoxidation products appears to increase in the order of vanadium, niobium, and tantalum reactions. The experimental results of the quantitative relation between those elements and oxygen in liquid iron equilibrated at the steelmaking temperature are shown in Fig. 6. One of the obvious features of these relations is that the deoxidizing power becomes larger in the order of vanadium, niobium, and tantalum, that is, in the order of increasing atomic number. The deoxidizing powers of vanadium and niobium are recognized to be situated between manganese and silicon, and that of tantalum is so much as silicon.

The interaction parameters, $\epsilon_{0}^{(M)}$ are shown in Fig. 7, and it is noticed that the activity of oxygen in liquid iron decreases with the increasing concentration of vanadium, niobium, or tantalum. It appears that the degree of their influence on the activity of oxygen becomes larger according to their deoxidizing powers.

\section{Summary}

From the study on the deoxidation equilibria of vanadium, niobium, and tantalum in liquid iron, the following results were obtained.

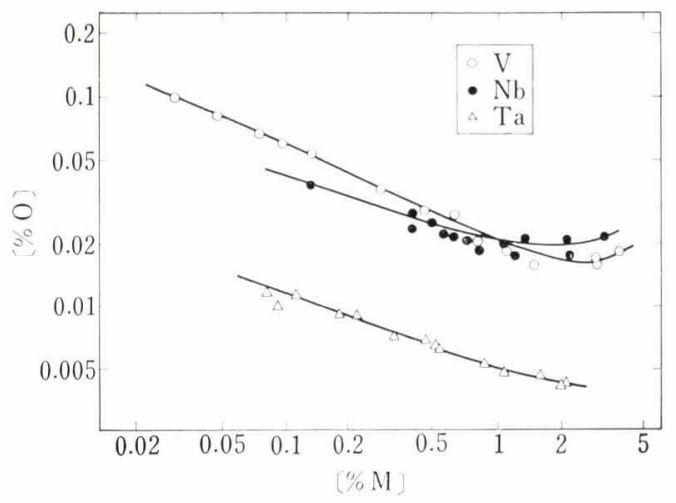

Fig. 6. Deoxidation equilibria of vanadium, niobium, and tantalum in liquid iron at $1600^{\circ} \mathrm{C}$

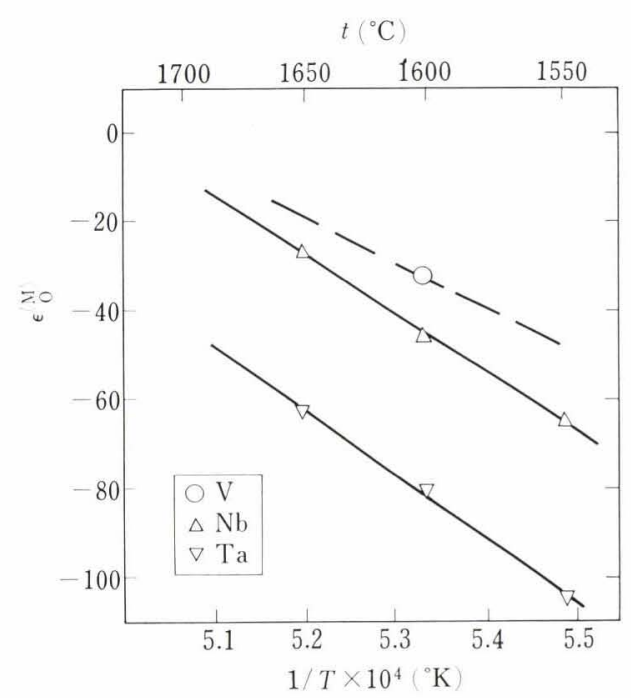

Fig. 7. Temperature dependence of interaction parameter, $\epsilon_{0}^{(\mathrm{M})}$

(1) The deoxidizing powers of vanadium, niobium, and tantalum become larger as the atomic number increases. Correspondingly, the influences of those elements on the activity of oxygen appear to become larger in the order of atomic numbers.

(2) The deoxidation products of vanadium, niobium, and tantalum in liquid iron are considered to be $\mathrm{V}_{2} \mathrm{O}_{3}, \mathrm{NbO}_{2}$, and $\mathrm{Ta}_{2} \mathrm{O}_{5}$, respectively, when the amounts of elements added are comparatively large. On the other hand, their deoxidation products appear to be formed as compounds with ferrous ion when the amounts of elements added are comparatively small.

\section{REFERENCES}

1) M. N. Dastur and J. Chipman: Trans. AIME., 185 (1949), 441.

2) V. V. Averin, A. Yu. Polyakov, and A. M. Samarin: Izv. Akad. Nauk SSSR, Otdel Tekh. Nauk, No. 3 (1955), 90.

3) N. A. Gokcen: Trans. AIME., 206 (1956), 1558.

4) T. P. Floridis and J. Chipman: Trans. AIME., 212 (1958), 549.

5) H. Sakao and K. Sano: Trans. Japan Inst. Metals, 1 (1960), 38.

6) S. Matoba and T. Kuwana: Tetsu-to-Hagané Overseas, 5 (1965), 187.

7) K. Narita: Bull. Chem. Soc. Japan, 79 (1958), 866.

8) K. Narita and S. Koyama: Published in the Autumn 
Grand Lecture of Japan Inst. Metals, Oct. (1965).

9) R. A. Karasev, A. Yu. Polyakov, and A. M. Samarin: Izv. Akad. Nauk SSSR, Otdel. Tekh. Nauk, No. 9 (1952), 1360.

10) K. Narita and S. Koyama: Tetsu-to-Hagané, 53 (1967), S 478.

11) K. Narita and M. Taniguchi: Kobe Steel Engineering Reports, 17 (1967), 280.

\section{Appendix}

(1) As mentioned in the preceding chapter, it is evident from the results of the present investigation that the equilibrating oxide as a deoxidation products in liquid iron containing comparatively small amount of niobium is niobite, i.e., columbite, $\mathrm{FeNb}_{2} \mathrm{O}_{6}$ having hexagonal structure, and that one for higher niobium content is niobium dioxide, $\mathrm{NbO}_{2}$ with tetragonal structure.

Taking account of the sizes of iron and niobium atoms and the stabilities of these crystal structures, it is theoretically expected that $\mathrm{FeNbO}_{3}$ of the ilmenite type with hexagonal structure is equilibrated in medial niobium content preceding to the formation of niobium dioxide. This oxide seems to belong to the type of $\alpha$ alumina $\left(\mathrm{Al}_{2} \mathrm{O}_{3}\right)$ as for the crystal structure. However, it seems that the crystal symmetry is poorer than that of $\alpha$-alumina and that the crystal lattice is distorted because of the large size of ferrous ion $\mathrm{Fe}^{2+}$. Consequently, its crystal structure is considered to take one of hexagonal, orthorhombic, or tetragonal.

In the present investigation, the formation of $\mathrm{FeNbO}_{3}$ has not been clarified yet. It seems to depend on the fact that this oxide is a transitional phase in $\mathrm{FeNb}_{2} \mathrm{O}_{6}$ $\rightleftarrows \mathrm{NbO}_{2}$ reactions and equilibrated at only narrow range of niobium content in liquid iron.

(2) As to the deoxidation reaction of tantalum in liquid iron:

(a) The reaction product equilibrated in the range of comparatively small tantalum concentration is ferrous tantalate, $\mathrm{FeTa}_{2} \mathrm{O}_{6}$ which has the same chemical composition as columbite. The oxide is commonly called tapiolite. Each of the investigators has their own view as to this oxide and its crystal structure has not necessarily been determined precisely.

According to the present study with the oxide formed in the liquid iron-tantalum-oxygen $(\mathrm{Fe}-\mathrm{Ta}-\mathrm{O})$ alloy, the result of X-ray diffraction accords well with tapiolite of trirutile type with tetragonal structure that is reported by Tavora and Peixoko in Anai da Academia Brasileira de Ciencias, 23 (1951), 449, or pseudo-tapiolite with tetragonal structure that is reported by Hutton in American Mining, 43 (1958), 112. The former is constructed by super lattice having the order configuration of metal atoms. The latter is constructed by disordered lattice, and is easily transformed to true-tapiolite by heating at comparatively high temperature. In any case, the equilibrated oxide in liquid iron containing less tantalum is ferrous tantalate which has the composition indicated by $\mathrm{FeTa}_{2} \mathrm{O}_{6}$, or more precisely, a double oxide indicated by $\left(\mathrm{Fe}^{2+}, 2 \mathrm{Ta}^{5+}\right) \mathrm{O}_{6}$ or $\left(1 / 3 \mathrm{Fe}^{2+}, 2 / 3 \mathrm{Ta}^{5+}\right) \mathrm{O}_{2}$.

(b) On the other hand, the equilibrated oxide in liquid iron containing comparatively large amount of tantalum is $\mathrm{Ta}_{2} \mathrm{O}_{5}$ having orthorhombic structure.

With respect to $\mathrm{Ta}_{2} \mathrm{O}_{5}$, there are $\alpha$-form becoming stable at high temperature, and $\beta$-form at relatively low temperature.

In the present investigation, X-ray diffraction pattern obtained accords with that determined by Reisman and others (J. Amer. Chem. Soc., 78 (1956), 4514, $\alpha$ $\left.\mathrm{Ta}_{2} \mathrm{O}_{5}\right)$, or by Battelle Memorial Institute $\left(\beta-\mathrm{Ta}_{2} \mathrm{O}_{5}\right)$. 